\title{
Comparison of cognitive and UHDRS measures in monitoring disease progression in Huntington's disease: a 12-month longitudinal study
}

Eng A Toh ${ }^{1,2^{*}}$, Michael R MacAskill ${ }^{1,2}$, John C Dalrymple-Alford ${ }^{1,2,3}$, Daniel J Myall2, Leslie Livingston ${ }^{1,2}$, Sandy AD Macleod ${ }^{4}$ and Tim J Anderson ${ }^{1,2,5}$

\begin{abstract}
Progressive cognitive decline is a feature of Huntington's disease (HD), an inherited neurodegenerative movement disorder. Comprehensive neuropsychological testing is the 'gold standard' to establish cognitive status but is often impractical in time-constrained clinics. The study evaluated the utility of brief cognitive tests (MMSE and MoCA), UHDRS measures and a comprehensive neuropsychological tests battery in monitoring short-term disease progression in HD. Twenty-two manifest HD patients and 22 matched controls were assessed at baseline and 12-month. A linear mixed-effect model showed that although the HD group had minimal change in overall global cognition after 12 months, they did show a significant decline relative to the control group. The controls exhibited a practice effect in most of the cognitive domain scores over time. Cognitive decline at 12-month in HD was found in the executive function domain but the effect of this on global cognitive score was masked by the improvement in their language domain score. The varying practice effects by cognitive domain with repeated testing indicates the importance of comparing HD patients to control group in research trials and that cognitive progression over 12 months in HD should not be judged by changes in global cognitive score. The three brief cognitive tests effectively described cognition of HD patients on cross-sectional analysis. The UHDRS cognitive component, which focuses on testing executive function and had low variance over time, is a more reliable brief substitute for comprehensive neuropsychological testing than MMSE and MoCA in monitoring cognitive changes in HD patients after 12 months.
\end{abstract}

Keywords: Huntington's disease, Disease progression, Cognition, UHDRS, Longitudinal

\section{Background}

Huntington's disease (HD) is an inherited neurodegenerative disease caused by expansion of CAG trinucleotide repeats secondary to mutation in the huntingtin gene on chromosome 4p16.3 [1]. The disease is characterized by involuntary hyperkinetic movements, cognitive impairment and behavioural disorders. Cognitive impairment, which may be evident even in gene-positive individuals yet to be clinically diagnosed [2-5], is progressive in nature and a contributing factor in the loss of everyday function [6]. Subtle cognitive impairment can be overlooked by clinicians during routine follow-up [7], indicating the need

\footnotetext{
* Correspondence: eng.toh@nzbri.org

'Department of Medicine, Christchurch School of Medicine \& Health Sciences, University of Otago, Christchurch, New Zealand

${ }^{2}$ New Zealand Brain Research Institute, Christchurch, New Zealand Full list of author information is available at the end of the article
}

for easily administered and yet robust tool to detect cognitive changes in HD. Comprehensive neuropsychological testing is necessary to verify cognitive status. However, neuropsychological batteries are time-consuming and brief cognitive screening tools such as the Mini Mental State Examination (MMSE) and the Montreal Cognitive Assessment (MoCA) are commonly used in clinical settings and in a broad range of conditions. The Unified Huntington's Disease Rating Scale (UHDRS), a standard assessment tool for $\mathrm{HD}$, also includes a brief cognitive component.

The MMSE [8] comprises eleven questions spanning five aspects of cognitive function: executive function, language, memory function, visuospatial ability and orientation. It has good inter-rater, test and re-test reliability in differentiating cognitive status in dementia syndromes [9] and other disorders featuring cognitive impairment [10]. 
Nevertheless, it is influenced by demographic factors such as age, education and cultural background $[9,11,12]$. The MoCA places greater emphasis than the MMSE on naming, attention, abstraction and delayed recall, functions that are most likely to be compromised in the earlier stages of cognitive impairment and unlike the MMSE, it compensates for education level [13]. Both the MMSE and MoCA have been employed as measures of cognitive performance in manifest HD patients [14-17] and MoCA was also found to have higher sensitivity without losing specificity than the MMSE in identifying those with cognitive impairment in HD [16]. Furthermore, Bezdicek et al. [17] demonstrated a strong correlation between the MoCA scores and comprehensive neuropsychological assessment scores in manifest HD patients. The UHDRS cognitive component [18] includes three tests of executive function - letter fluency test, Symbol Digit Modalities test and Stroop test; which can be used with corrected norms to attenuate the impact of various demographic variables $[19,20]$.

The progressive nature of HD means that any cognitive assessments should also be useful longitudinally. HD patients are routinely followed up at clinics at 6month and 12-month intervals thus it is preferable that brief cognitive assessment tools are sensitive to changes even over relatively short time intervals. Effective yet brief cognitive tools would enable easier detection of cognitive changes in HD patients in clinic settings than time consuming comprehensive cognitive assessment and also assist health care providers in designing treatment and care plans aimed at improving patient's quality of life. MMSE and MoCA have been extensively evaluated in previous cross-sectional HD studies [14-16] but to our knowledge, there is no longitudinal data on the utility of these brief cognitive tests compared to UHDRS cognitive assessment in monitoring cognitive changes in HD patients. Therefore the objective of this study was to examine and compare the relative utility of two widely used brief cognitive tests (MMSE and MoCA) concurrently with the UHDRS cognitive assessment to a comprehensive neuropsychological test battery for monitoring cognitive changes in HD patients over a short interval of 12 months. Such a direct comparison has not been previously reported.

\section{Methods}

Study participants were a convenience sample of 22 manifest HD patients (10 males and 12 females) with mild to moderate disease severity and 22 age, gender and education matched control volunteers recruited through the New Zealand Brain Research Institute database (Table 1). Patients were genetically verified and clinically diagnosed by a movement disorders specialist (TJA). Participants identified themselves as native speakers of
Table 1 Demographic characteristics (mean and SD) of control and HD groups

\begin{tabular}{lcc}
\hline & \multicolumn{2}{c}{ Mean (SD) } \\
\cline { 2 - 3 } & $\begin{array}{c}\text { Control group } \\
\mathbf{n}=\mathbf{2 2}\end{array}$ & $\begin{array}{c}\text { HD group } \\
\mathbf{n}=\mathbf{2 2}\end{array}$ \\
\hline Age & $50(15)$ & $50(15)$ \\
\hline CAG repeat no. & - & $44(4)$ \\
\hline Education level (years) & $13(2)$ & $13(2)$ \\
\hline Follow-up interval (weeks) & $53(3)$ & $54(4)$ \\
\hline Retention rate at 12-month & $91 \%(n=20)$ & $100 \%(n=22)$ \\
\hline
\end{tabular}

English and consented to participate in compliance with the requirements of the New Zealand Ministry of Health Ethics Committee.

\section{Experiment procedure}

The MMSE, MoCA and a comprehensive neuropsychological test battery were administered to all participants. The comprehensive assessment of cognitive function used 19 neuropsychological tests to assess six domains of cognitive function (executive function; working memory and attention; learning and memory; processing speed; language; and visuospatial function). These tests were: executive function: letter, action and category fluency tests [21], Trail Making Test (Part B), Stroop-interference test; working memory and attention: digits forward, backward and sequencing tests [22], Symbol Digit Modalities Test [23] and Ruff 2 \& 7 Cancellation Test - Accuracy [24]; learning and memory: Short California Verbal Learning Test-II and Brief Visuospatial Memory Test-Revised; processing speed: Stroop-word reading, Stroop-colour naming, Trail Making Test (Part A) and Ruff 2 \& 7 Cancellation Test - Speed; language: Brief Boston Naming Test [25] and Indiana University Token Test [26]; and visuospatial function: Judgement of Line Orientation test (Form $\mathrm{H}$ ) and Rey Complex Figure Copying test. For the MMSE, both alternatives ('World' spelled backwards and serial sevens) were assessed. The number of tests administered was evenly distributed over two separate sessions, one week apart and presented in the same order for all participants. Each session began with the MMSE in the first and MoCA in the second session. The three-part UHDRS, comprising motor, cognitive and behavioural components, was administered in the first session to the HD group only. All returning participants were reassessed in identical manner 12 months later.

\section{Data analysis}

Cognitive status - normal, mild cognitive impairment (MCI) or dementia - of HD participants was determined using evidence from the neuropsychological test battery and the UHDRS. Criteria for mild cognitive impairment (MCI) followed that described for Parkinson's disease by 
Dalrymple-Alford et al. [27], with a requirement of 2 measures at $-1.5 \mathrm{SD}$ or equivalent within a single domain; and dementia criteria followed that of Peavy et al. [5], which defined HD dementia as having cognitive deficits in at least two areas of cognition not limited to memory deficits in the context of impaired everyday function as determined through the UHDRS Functional Independence Scale.

The raw score of each component test in the neuropsychological test battery was converted to a standard z-score using test-specific norms so that objective comparison can be made across component tests, regardless of individual scale ranges and distributions. Domainspecific scores were mean aggregated scores of component tests within a cognitive domain and the average scores across all six cognitive domains determined the global cognitive z-score (overall global cognition). The MoCA scores were adjusted to participants' education level [13]. The three cognitive tests (letter fluency, SDMT and Stroop tests) in the UHDRS cognitive component were part of the neuropsychological test battery so the mean aggregate $\mathrm{z}$-score of these tests was used as the UHDRS cognitive score for both the HD and control groups.

\section{Statistical analysis}

For each of the measures, the differences between groups at baseline and the change over 12 months were determined using linear mixed-effects models [28]. These models take into account the correlated measurements within a participant when assessing the differences between groups and changes over time. The relationship between global cognition and brief cognitive tests, baseline and 12-month scores were assessed using $R^{2}$ correlation coefficient from simple linear models. Bootstrapping [29] was used to assess differences between $R^{2}$ correlation coefficients as standard analytical techniques were not applicable. Bootstrapping involved the original sample being resampled with replacement and the difference between $R^{2}$ values in this new sample being determined. This was repeated 1000 times and the resulting distribution of differences in $R^{2}$ values gave an indication of the mean difference and a 95\% confidence interval. Cohen's $d$ was used to report effect sizes of differences between groups.

\section{Results}

\section{Cognition at baseline and change over time}

At baseline, six HD patients had normal cognition, 10 met criteria for MCI, and six had dementia [5]. All 22 controls had normal cognition. The HD group showed significantly reduced scores $(t>3.5, p \leq 0.001)$ in overall global cognition and brief cognitive tests compared to controls both at baseline and at 12-month follow-up. The mean effect sizes for the two years combined in overall global cognition was $d=2.6$ whereas in the brief cognitive tests, they ranged from $d=1.3$ in the MMSE with 'World' spelled backwards to $d=2.4$ in UHDRS cognitive assessment (Figure 1A, Table 2). In terms of domain-specific scores, the HD group had significantly lower scores $(t>4.7, p<0.001)$ compared to controls across all cognitive domains and the mean effect sizes for baseline and 12-month combined ranged from the smallest $(d=1.5)$ in the language domain to the largest $(d=2.8)$ in the executive function domain (Figure 1B, Table 2). Individual component test scores in HD and control groups at baseline and 12-month are detailed in Additional file 1: Figure S1 and brief cognitive tests in Additional file 2: Table S1.

There was an overall pattern of improvement in the control group across all cognitive tests after 12 months. In contrast, the HD group showed minimal change in their global cognitive z-score and a general decline across all brief cognitive tests scores after 12 months, for which it was statistically significant $(t<-2.0, p=0.048)$ in UHDRS cognitive score and MMSE with 'World' spelt backwards (Figure 1A, Table 2). The control group exhibited an increase in score at 12 months in most cognitive domains $(t>2.2, p<0.04)$ excepting executive function and visuospatial domains $(t<1.6, p>0.1)$. Contrastingly, the HD group demonstrated a decline $(t=2.3, p=0.03)$ in executive function domain but an increase $(t=2.7, p=0.01)$ in language domain $\mathrm{z}$-score 12 months later. There were no significant absolute changes $(t<1.2, p>0.3)$ in the other cognitive domains in the HD group (Figure 1B, Additional file 2: Figure S1). A relative change over time (i.e. relative deterioration) in the HD group compared to change in scores in the control group was significant for global cognitive z-score, MMSE with 'World' spelled backwards, executive function, and learning and memory domain scores (Table 2). There was a significant worsening $(t=3.9, p<$ 0.001 ) of the UHDRS motor score over 12 months in the HD group but no change in behavioural score (Table 2).

\section{Usefulness of scores for measuring change over time}

There are several considerations to take into account when determining which brief cognitive test has greatest utility for measuring cognition over time. This includes how well the score reflects overall global cognition, whether there is any ceiling effect, and how noisy (variability of score residuals) the score is after taking systematic changes into consideration.

Simple linear models confirmed that scores of all three brief cognitive screening tests, as judged by their $R^{2}$ values, were significantly correlated with the scores of the full neuropsychological test battery at baseline (Figure 2) and 12-month (not shown). Bootstrap procedures confirmed that there were no significant differences between the three brief cognitive screening tests in extent 


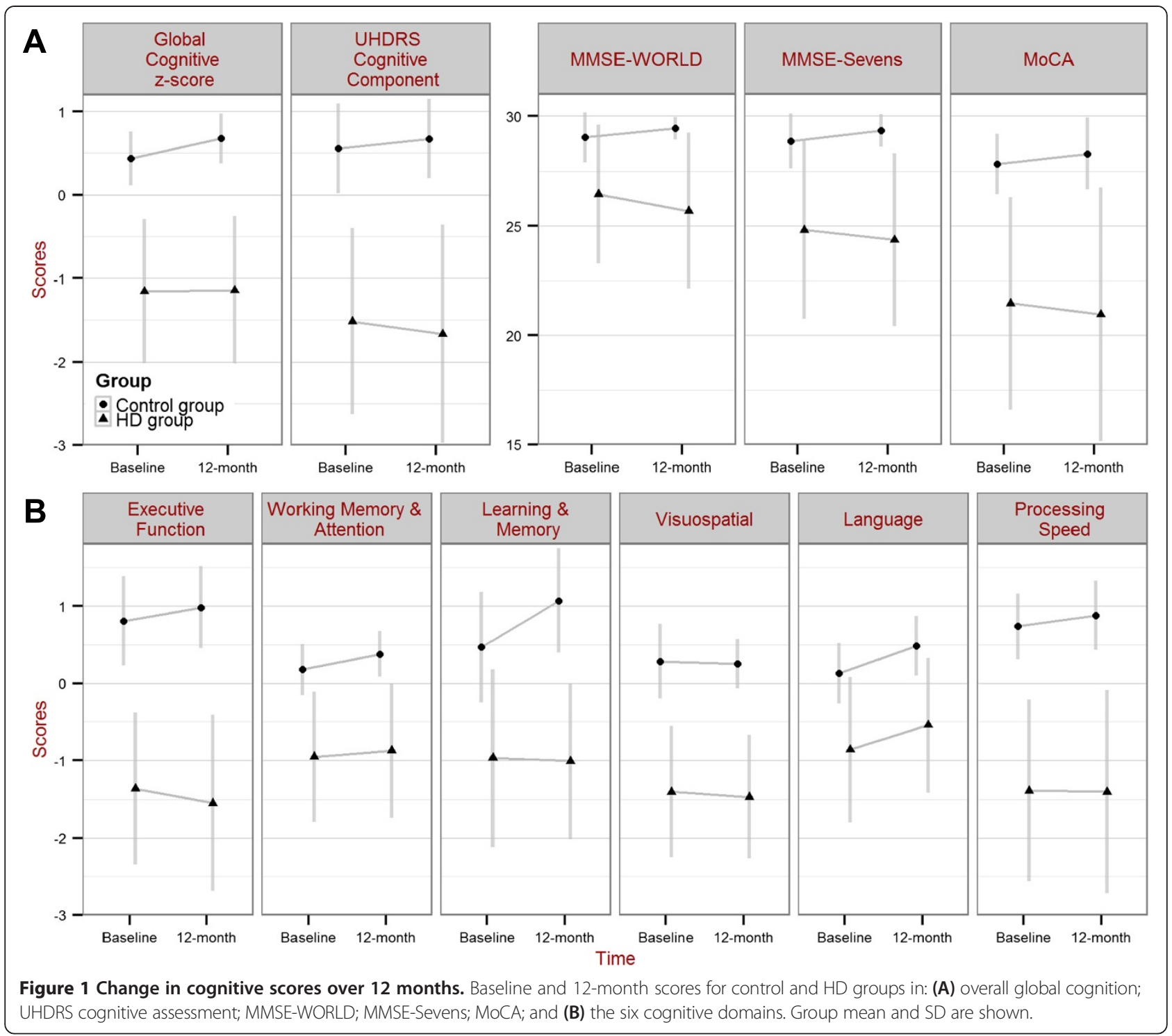

of correlation with overall global cognition (Table 3). Thus all brief cognitive tests provided a reasonable crosssectional measure of global cognition.

To determine the variability of score residuals over time, simple linear models were fitted to the baseline and 12-month scores of overall global cognition and brief cognitive tests. The correlations within a test over time were evaluated by examining the $R^{2}$ values of the model fits (Figure 3). In the control group, the range of scores in MMSE and MoCA was narrow due to a ceiling effect hence contributing to $R^{2}$ values $\left(R^{2}<0.36\right)$. In contrast, the global z-score and UHDRS cognitive component showed greater utility in the control group, with a wider range of values together and small deviations from the linear fit, resulting in high $R^{2}$ values. In the HD group the baseline scores were well correlated $\left(R^{2}>\right.$ 0.67 ) with 12 -month scores for overall global cognition and all three brief cognitive tests (Figure 3). The comprehensive neuropsychological test battery and UHDRS cognitive component, as confirmed by bootstrap procedures, had smaller deviations from the linear fit than the two versions of the MMSE but not the MoCA (Table 4). This finding indicates that the two versions of MMSE had higher measurement noise (i.e. greater score variability over time), compared to overall global cognition and UHDRS cognitive assessment after 12 months.

In summary, the combination of showing a significant decline of cognition in HD (Table 2), high correlation with global cognitive z-score (Figure 2), and lower variance of score residuals over time (Figure 3) compared to other brief cognitive assessments, indicated the UHDRS cognitive component performed the best of the brief cognitive tests in assessing and monitoring cognition in HD patients over a 12-month period. 
Table 2 Scores" at baseline, within-group changes and group over time interactions of control and HD groups

\begin{tabular}{|c|c|c|c|c|c|}
\hline \multirow{3}{*}{ Measures } & \multicolumn{5}{|c|}{ z-scores } \\
\hline & \multicolumn{2}{|c|}{ Control group } & \multicolumn{2}{|r|}{ HD group } & \multirow{2}{*}{$\begin{array}{c}\text { HD vs. Controls } \\
\text { Relative change after } 12 \text { months } \\
\text { Mean }[95 \% \mathrm{Cl}]\end{array}$} \\
\hline & $\begin{array}{c}\text { Baseline } \\
\text { Mean }[95 \% \mathrm{Cl}]\end{array}$ & $\begin{array}{l}\text { Change after } 12 \text { months } \\
\text { Mean }[95 \% \mathrm{Cl}]\end{array}$ & $\begin{array}{c}\text { Baseline } \\
\text { Mean }[95 \% \mathrm{Cl}]\end{array}$ & $\begin{array}{l}\text { Change after } 12 \text { months } \\
\text { Mean }[95 \% \mathrm{Cl}]\end{array}$ & \\
\hline $\begin{array}{l}\text { Overall global } \\
\text { cognition }\end{array}$ & $0.4[0.2-0.7]$ & $0.2[0.1-0.3], p<0.001$ & $-1.2[-1.4--0.9]$ & $0.01[-0.1-0.1], p=0.8$ & $-0.2[-0.4--0.1], p=0.006$ \\
\hline Executive function & $0.8[0.4-1.2]$ & $0.1[-0.04-0.1], p=0.1$ & $-1.4[-1.7--1.0]$ & $-0.2[-0.4--0.02], p=0.03$ & $-0.3[-0.6--0.1], p=0.01$ \\
\hline $\begin{array}{l}\text { Working memory \& } \\
\text { attention }\end{array}$ & $0.2[-0.1-0.5]$ & $0.2[0.05-0.3], p=0.01$ & $-1.0[-1.2--0.7]$ & $0.08[-0.1-0.2], p=0.3$ & $-0.1[-0.3-0.1], p=0.3$ \\
\hline Learning \& memory & $0.5[0.1-0.9]$ & $0.6[0.3-0.9], p<0.001$ & $-1.0[-1.4--0.6]$ & $-0.04[-0.3-0.2], p=0.8$ & $-0.6[-1.0--0.3], p<0.001$ \\
\hline Processing speed & $0.7[0.3-1.1]$ & $0.1[0.01-0.03], p=0.04$ & $-1.4[-1.8--1.0]$ & $-0.01[-0.1-0.1] p=0.8$ & $-0.2[-0.3-0.02], p=0.09$ \\
\hline Language & $0.1[-0.2-0.4]$ & $0.3[0.1-0.6], p=0.008$ & $-0.9[-1.2--0.6]$ & $0.3[0.1-0.6], p=0.01$ & $-0.02[-0.4-0.3], p=0.9$ \\
\hline Visuospatial & $0.3[0.0-0.6]$ & $-0.02[-0.2-0.2], p=0.8$ & $-1.4[-1.7--1.1]$ & $-0.07[-0.2-0.3], p=0.5$ & $-0.04[-0.3-0.2], p=0.8$ \\
\hline \multirow[t]{2}{*}{$\begin{array}{l}\text { UHDRS cognitive } \\
\text { score }\end{array}$} & $0.6[0.2-1.0]$ & $0.06[-0.1-0.2], p=0.5$ & $-1.5[-1.9--1.1]$ & $\begin{array}{c}-0.2[-0.3--0.001], p= \\
0.048\end{array}$ & $-0.2[-0.4-0.01], p=0.06$ \\
\hline & \multicolumn{5}{|c|}{ Points } \\
\hline \multirow{2}{*}{ Measures } & \multicolumn{2}{|c|}{ Control group } & \multicolumn{2}{|r|}{ HD group } & HD vs. Controls \\
\hline & $\begin{array}{c}\text { Baseline } \\
\text { Mean }[95 \% \mathrm{Cl}]\end{array}$ & $\begin{array}{l}\text { Change after } 12 \text { months } \\
\text { Mean }[95 \% \mathrm{Cl}]\end{array}$ & $\begin{array}{c}\text { Baseline } \\
\text { Mean }[95 \% \mathrm{Cl}]\end{array}$ & $\begin{array}{l}\text { Change after } 12 \text { months } \\
\text { Mean }[95 \% \mathrm{Cl}]\end{array}$ & $\begin{array}{l}\text { Relative change after } 12 \text { months } \\
\text { Mean }[95 \% \mathrm{Cl}]\end{array}$ \\
\hline \multicolumn{6}{|l|}{ MMSE } \\
\hline with WORLD item & $29[28-30]$ & $0.4[-0.3-1.1], p=0.3$ & $26[25-28]$ & $-0.8[-1.5-0.08], p=0.03$ & $-1.2[-2.2--0.2], p=0.02$ \\
\hline with Sevens item & $29[28-30]$ & $0.5[-0.4-1.4], p=0.3$ & $25[24-26]$ & $-0.5[-1.3-0.4], p=0.3$ & $-1.0[-2.2-0.3], p=0.1$ \\
\hline MoCA & $28[26-30]$ & $0.4[-0.6-1.4], p=0.5$ & $21[20-23]$ & $-0.5[-1.5-0.5], p=0.3$ & $-0.9[-2.3-0.5], p=0.2$ \\
\hline UHDRS motor score* & - & - & $42[33-51]$ & $7.4[3.4-11.3], p<0.001$ & - \\
\hline $\begin{array}{l}\text { UHDRS behavioural } \\
\text { score* }^{*}\end{array}$ & - & - & $23[17-30]$ & $0.7[-6.4-7.8], p=0.8$ & - \\
\hline
\end{tabular}

*UHDRS motor and behavioural components were assessed in the HD group only.

\#Baseline and 12-month SD and ranges for all variables are detailed in Additional file 2: Table S1 and score changes after 12 months in individual component tests are shown in Additional file 1: Figure S1.

\section{Discussion}

This study attempted to evaluate the usefulness of two widely used brief cognitive assessment tools (MMSE and MoCA) simultaneously with UHDRS cognitive component for monitoring cognitive changes in manifest $\mathrm{HD}$ patients over a 12-month interval by comparing them to a comprehensive neuropsychological test battery. In the process of evaluating the usefulness of these brief cognitive tests, we demonstrated that there was no significant change in overall global cognition in the presence of significant decline in the executive function domain in manifest HD patients after 12 months. Relative to the control group, which showed an increase in overall global cognitive z-score and learning and memory domain score over a 12-month period, there was significantly less change in domain-specific scores in the HD group over that period. The MMSE and MoCA were less effective than the UHDRS cognitive assessment for monitoring cognitive changes in manifest HD patients over 12 months.

\section{Domain-specific cognitive performance}

Cognitive decline, which has been shown to assume a relatively slow course especially in the early stages of
HD [30-33], is a well-established hallmark of HD. Overall, our findings corroborated with other longitudinal studies on pre-manifest and early manifest HD patients wherein, relative to a control group, cognitive decline were evident after a 12-month interval in the HD group [30] and, similar conclusions were made at 24-month follow-up [31]. The significant decline in executive function domain score in the HD score was consistent to a study by Bachoud-Lévi et al. [32], which demonstrated that cognitive deterioration in early stages patients is limited to attention and executive functions. However, unlike their study which also showed significant changes in visuospatial and language functions over time, such changes were not evident in our study suggesting that such changes were limited in early HD and not across different stages of HD. Executive function domain has always been recognized to be the most vulnerable in HD [34] with progressive impairment evident not just in early stages of HD [32,35] but also in pre-manifest HD patients [36].

In contrast to the HD group, which had minimal change in overall global cognition over time, the control group had a significant improvement in their scores over time. 


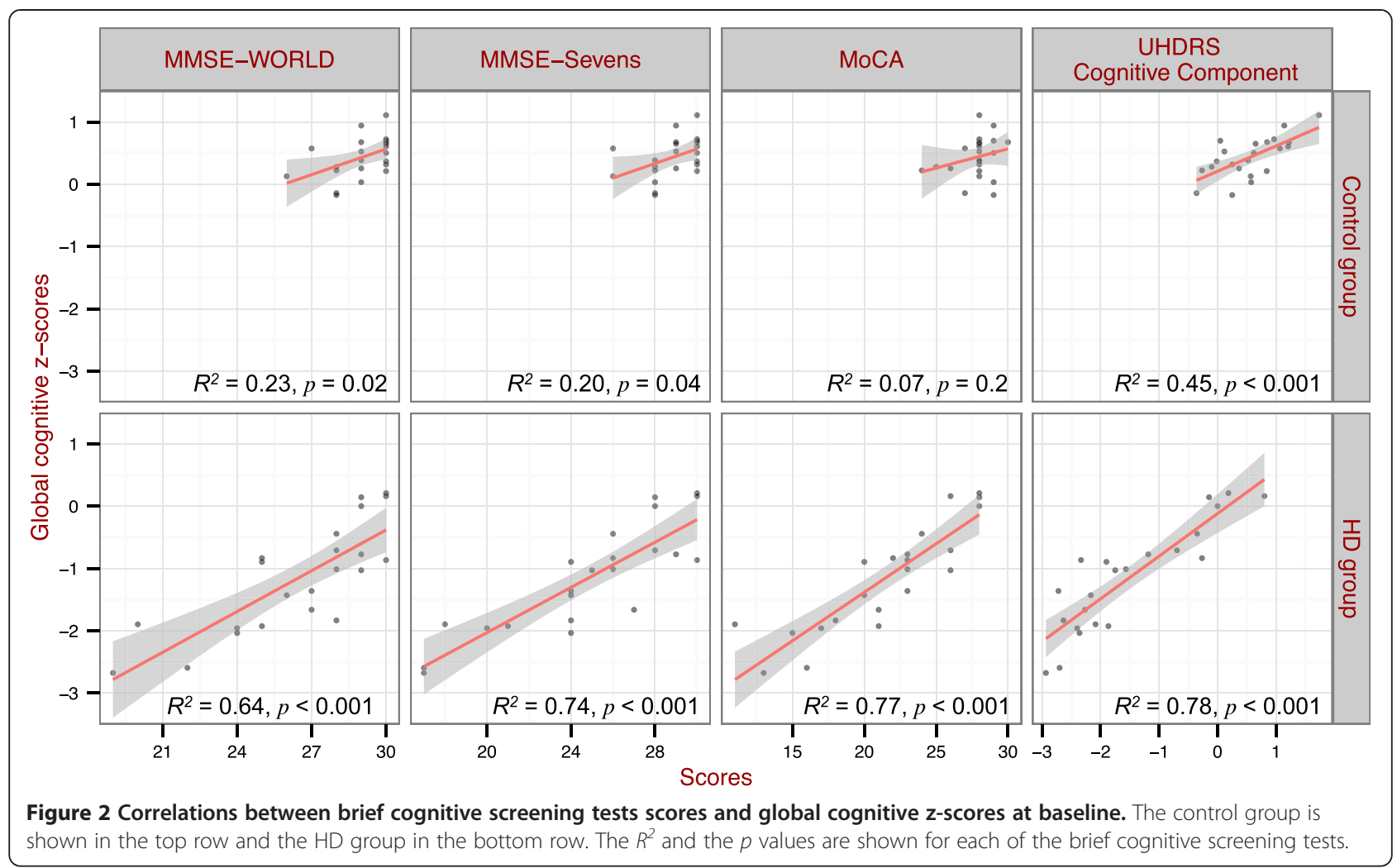

This suggested that controls had in general benefitted from practice effect on repeated testing of measures in the comprehensive neuropsychological test battery. This was consistent to previous works on cognitive performance in healthy controls in longitudinal studies $[37,38]$. Practice effect in healthy controls is most apparent in the early phases of repetitive testing, with performance scores tending to plateau on subsequent testing [39,40], or after changing to low frequency testing [41]. Atrophy of the caudate nucleus, a structure involved in learning process, is found in normal aging process but this process when compared to healthy controls, occurs at an expedited rate in HD patients as demonstrated through serial radio-imaging studies $[31,42]$. Nevertheless, as already reported in a 2 to 4 year longitudinal study on cognition in early HD patients, practice effect was evident in certain executive function and memory related tests between first and second assessments [32]. Although it was reported in that same study [32] that practice effect was not observed in language

Table 3 Comparison of $R^{2}$ differences of relationships between brief cognitive tests and full cognitive battery

\begin{tabular}{lccc}
\hline & \multicolumn{3}{c}{ Differences in $R^{2}$ values [95\% Cl] } \\
\cline { 2 - 4 } & MMSE - WORLD & MMSE - Sevens & MoCA \\
\hline $\begin{array}{c}\text { UHDRS cognitive } \\
\text { component }\end{array}$ & $0.1[-0.0-0.4]$ & $0.1[-0.1-0.3]$ & $0.0[-0.2-0.2]$ \\
\hline MMSE - WORLD & - & $-0.1[-0.3-0.1]$ & $-0.1[-0.4-0.0]$ \\
\hline MMSE - Sevens & - & - & $-0.0[-0.2-0.1]$ \\
\hline
\end{tabular}

performance, our HD cohort had actually shown a significant improvement in language domain score after 12 months. These findings suggested that HD patients indeed could benefit from practice effect over a relative short time interval and also showed that underlying disease progression may not be translated to measurable cognitive performance changes over short time interval.

Our findings reaffirmed the general slow progression of cognitive deterioration in $\mathrm{HD}$ patients over short time interval which inevitably create great difficulty in monitoring cognitive changes in HD patients on routine follow-up in clinic settings. Longitudinal monitoring of disease progression is generally conducted to evaluate potential interventions for delaying phenoconversion in $\mathrm{HD}$ thus the generally accepted view is that it is more meaningful to serially evaluate disease progression of pre-manifest HD patients. However, understanding short-term changes and the utility of various cognitive tools in manifest HD patients are also important for multi-disciplinary health team in planning and modifying disease management plans which consists of currently available pharmacological and nonpharmacological interventions aimed at improving patient's quality of life. Nevertheless, our findings have implications for clinical practice and research. Cognitive decline in HD appeared to be specific in executive function and learning and memory domains after 12 months. Therefore in the clinic, cognitive deterioration in HD over 12-month should not be determined by changes in overall global cognitive 

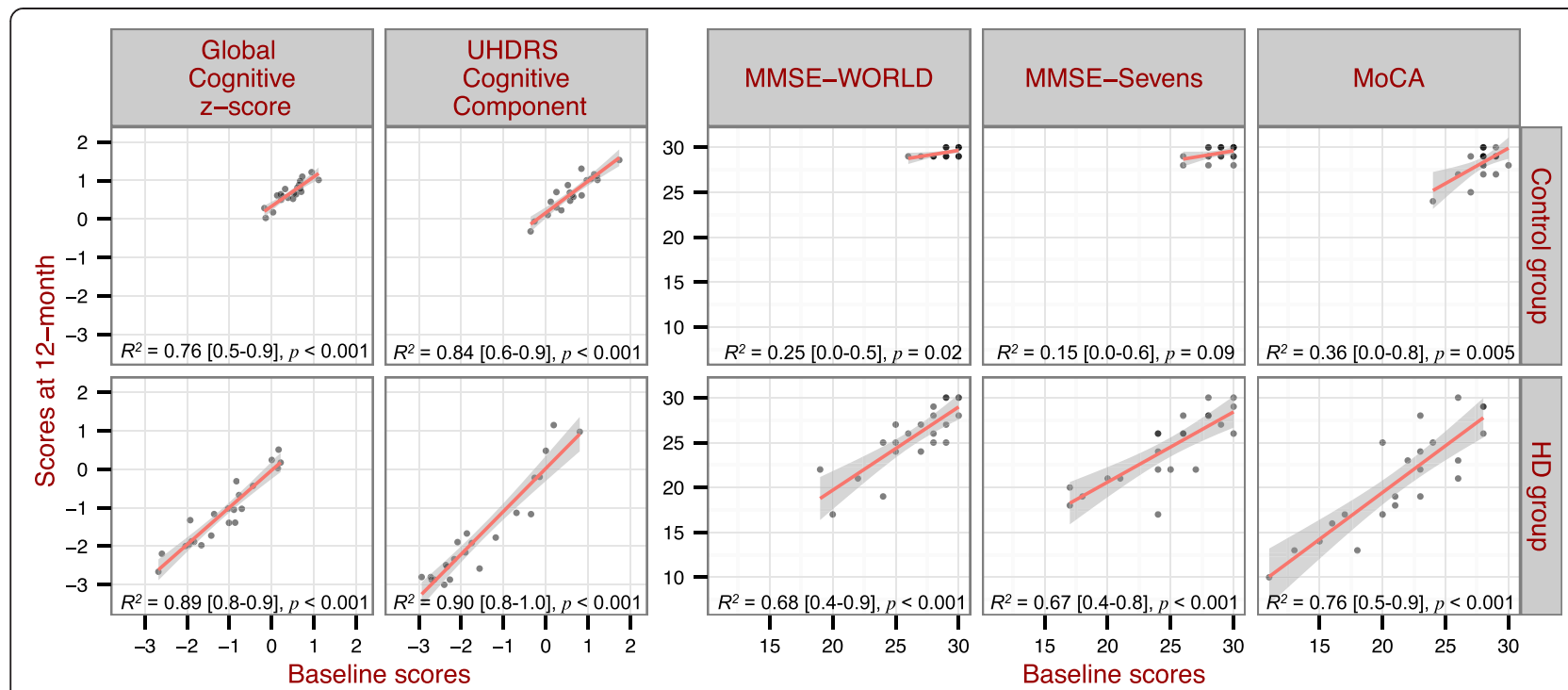

Figure 3 Correlations between baseline and 12-month scores of the five cognitive measures. Control group is shown in the top row and HD group in the bottom row. The $R^{2}, 95 \% \mathrm{Cl}$ (in square brackets) and $p$ values of the relationship are shown for each of the cognitive measures.

score of comprehensive neuropsychological test battery but by detailed analysis of cognitive domain-specific performance. Due to practice effect, it is important in short to medium term longitudinal clinical research to include a control group when assessing the cognition of HD patients.

\section{Usefulness of brief cognitive tests for longitudinal assessment}

As expected, the MMSE, MoCA and the UHDRS cognitive component scores correlated well with overall global cognition, as determined through the comprehensive neuropsychological test battery, in the HD group. These findings support the utility of the three brief cognitive assessment tools in cross-sectional detection of cognitive deficits in manifest HD patients. Furthermore, our findings showed that there were no significant differences between the three brief cognitive tests in reflecting overall global cognition in HD patients, providing no evidence that one test is better than the other in this respect.

However, the baseline scores of comprehensive neuropsychological test battery (overall global cognition) and UHDRS cognitive assessment were highly correlated with their 12-month scores and as judged by the $95 \% \mathrm{CI}$ of $R^{2}$ values, both types of assessment had minimal deviations from the linear fit indicated that both tests were reliable and had low score variability over time. The reliability of the MMSE in the HD group, though reasonable, was significantly lower than that for the full neuropsychological test battery and the UHDRS cognitive component. Deficiencies in reliability of MMSE were highlighted in a study by Bowie et al. [43], which inferred that the test was inadequate in detecting small cognitive changes. Moreover, large score variance on annual assessment was another weakness of MMSE as shown in a study on patients with Alzheimer's disease [44], which further limits its value in assessing disease progression. Similarly in our HD sample, the two versions of MMSE were found to have greater score variance than the comprehensive neuropsychological test battery and the UHDRS cognitive component. Even though the present study demonstrated that there were significant within-group changes after a 12-month period in the MMSE (with 'World' spelled backwards) in our HD patients, its use in routine follow-up in clinical practice should be interpreted with caution because of its tendency to vary from one assessment to the next. On the contrary, the MoCA and UHDRS cognitive component,

Table 4 Comparison of $R^{2}$ differences of relationships between baseline and 12-month scores in cognitive measures

\begin{tabular}{ccccc}
\hline & \multicolumn{4}{c}{ Differences in $\boldsymbol{R}^{2}$ values [95\% Cl] } \\
\cline { 2 - 6 } & UHDRS cognitive component & MMSE - WORLD & \multicolumn{1}{c}{ MMSE - Sevens } & MoCA \\
\hline Global cognitive z-score & $-0.0[-0.1-0.1]$ & $0.2[0.0-0.4]^{*}$ & $0.2[0.0-0.5]^{*}$ & $0.1[-0.0-0.3]$ \\
\hline UHDRS cognitive component & - & $0.2[0.0-0.5]^{*}$ & $0.2[0.0-0.4]^{*}$ & $-0.1[-0.0-0.4]$ \\
\hline MMSE - WORLD & - & - & $0.0[-0.2-0.1]$ & $-0.1[-0.3-0.1]$ \\
\hline MMSE - Sevens & - & - & - & $-0.1[-0.3-0.2]$ \\
\hline
\end{tabular}

*The estimated $95 \% \mathrm{Cl}$ of $R^{2}$ differences is greater than '0.0' which suggests that the difference in $R^{2}$ values between the two cognitive measures tested could be considered significant. 
as judged by the differences of $R^{2}$ values from linear fit models using bootstrap procedure, had comparable performance to the comprehensive neuropsychological battery. Such findings are likely to be attributed by the nature of short-term cognitive progression in HD which is specific to executive function and also the overall design of the tests. The MoCA, which was claimed to have superior sensitivity for detecting MCI compared to MMSE, contains more demanding tasks for assessing executive and memory functions [45] while the UHDRS cognitive component essentially assesses the executive function domain. However, MoCA is an assessment tool that examines multiple cognitive domains hence similar to the overall global cognitive score of comprehensive neuropsychological battery, short-term cognitive decline in HD patients could be masked by practice effect in other domains within the test.

On the basis of high correlation to comprehensive neuropsychological battery and low variance across time, the UHDRS cognitive component is a good brief substitute for comprehensive neuropsychological testing and a sensitive cognitive measure to assess short-term cognitive changes in HD patients compared to MMSE and MoCA. However, the MoCA and MMSE, in that order, might be considered as reasonable alternatives to the 'gold standard' for use in clinic setting in circumstances where the UHDRS cognitive component is unavailable but secondary to the limitations of MMSE and MoCA, their results shall be interpreted discretely.

\section{Other disease measures}

There was no significant worsening in the UHDRS behavioural score within our HD group at follow-up, similar to prior observations [18]. Behavioural abnormalities in $\mathrm{HD}$ are heterogeneous in nature and without clear temporal progression [46]. Furthermore, psychiatric interventions are often effective in managing behavioural disturbances of HD patients [47] so such features are less likely to exhibit progressive deterioration over time. Thus, the UHDRS behavioural index is not particularly useful as a measure of short to medium term disease progression in HD. In contrast to the absence of measurable change in the behavioural measure, there was a significant increase in the UHDRS motor score over 12 months. This is consistent with the Huntington Study Group's [18] report of an average three points increase in motor score over six months in manifest HD patients. The ability to demonstrate increase in the UHDRS motor score is not exclusive to manifest HD patients, with another study on pre-manifest patients showing that while the change was minimal after one year, there was significant increase in motor scores over five years [48]. These observations combined suggest that motor deterioration is possibly more aggressive in the short term than cognitive and behavioural changes in HD patients. However, the interpretation of the study findings was undoubtedly constrained by its small sample size and also limited number of patients in different disease stages.

\section{Concluding remarks}

Although MMSE and MoCA have been evaluated in previous cross-sectional HD studies [14-16], the utility of these brief cognitive tests has not been appraised longitudinally. This study provided a new perspective on the utility of two widely used brief cognitive assessment tools (MMSE and MoCA) in comparison to UHDRS cognitive assessment and other measures for monitoring cognitive changes in manifest HD patients over a 12-month period. MMSE and MoCA may be effective for describing global cognition in HD patients in cross-sectional analysis but they are less useful for monitoring longitudinal cognitive changes over short time interval. The UHDRS cognitive assessment, which focuses on testing executive function, is sensitive to short-term cognitive changes in $\mathrm{HD}$ and a more reliable brief assessment tool compared to MMSE and MoCA over 12 months. Nevertheless, our findings on the utility of these assessment tools in a restricted cohort of HD patients should be interpreted discretely and further studies on these brief cognitive tests are warranted in the future.

\section{Additional files}

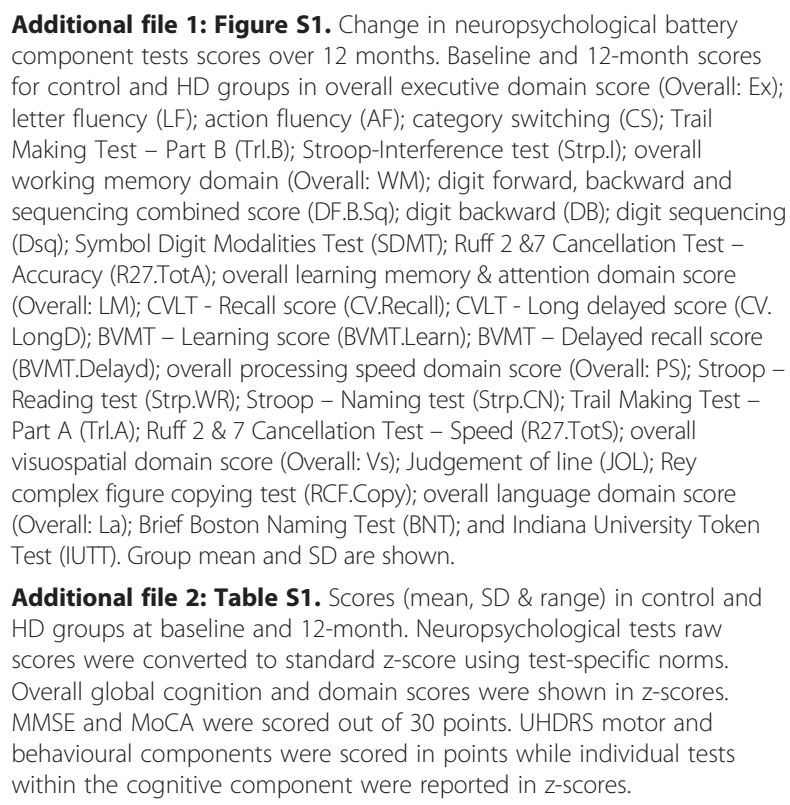

Additional file 2: Table S1. Scores (mean, SD \& range) in control and $\mathrm{HD}$ groups at baseline and 12-month. Neuropsychological tests raw scores were converted to standard z-score using test-specific norms. Overall global cognition and domain scores were shown in z-scores. MMSE and MoCA were scored out of 30 points. UHDRS motor and behavioural components were scored in points while individual tests within the cognitive component were reported in z-scores.

\section{Abbreviations}

HD: Huntington's disease; MCl: Mild cognitive impairment; MMSE: Mini Mental State Examination; MoCA: Montreal Cognitive Assessment; SD: standard deviation; UHDRS: Unified Huntington's Disease Rating Scale; (95\% Cl): 95\% confidence interval. 


\section{Competing interests}

The authors declare that there are no conflicts of interest in this research.

\section{Authors' contributions}

The study was conceptualised by EAT, MRM, JDA and TJA. EAT was the main author and analyzed the data, MRM evaluated the manuscript structure, ideas and science, JDA reviewed the manuscript structure, ideas and science, DJM was the main advisor for statistical analyses and appraised the manuscript structure and ideas, LL reviewed manuscript ideas, ADM reviewed the manuscript, TJA evaluated the manuscript structure, ideas and science. The final manuscript was read and approved by all authors.

\section{Acknowledgements}

The study was supported by grants from McGee Fellowship fund and a University of Otago Doctoral Scholarship. The authors are grateful to the HD patients, healthy controls and Ms. Maggie Jury, coordinator of clinical services for HD patients in Christchurch, for their participation and support in this project.

\section{Author details}

'Department of Medicine, Christchurch School of Medicine \& Health Sciences, University of Otago, Christchurch, New Zealand. ${ }^{2} \mathrm{New}$ Zealand Brain Research Institute, Christchurch, New Zealand. ${ }^{3}$ Department of Psychology, University of Canterbury, Christchurch, New Zealand. ${ }^{4}$ Brain Injury Rehabilitation Service, Canterbury District Health Board, Christchurch, New Zealand. ${ }^{5}$ Department of Neurology, Canterbury District Health Board, Christchurch, New Zealand.

Received: 28 March 2014 Accepted: 6 July 2014

Published: 12 July 2014

\section{References}

1. Huntington Disease Collaborative Research Group: A novel gene containing a trinucleotide repeat that is expanded and unstable on Huntington's disease chromosomes. The Huntington's Disease Collaborative Research Group. Cell 1993, 72:971-983.

2. Blackmore L, Simpson SA, Crawford JR: Cognitive performance in UK sample of presymptomatic people carrying the gene for Huntington's disease. J Med Genet 1995, 32:358-362.

3. Duff K, Paulsen J, Mills J, Beglinger LJ, Moser D, Smith MM, Langbehn D, Stout J, Queller S, Harrington DL: Mild cognitive impairment in prediagnosed Huntington disease. Neurology 2010, 75:500-507.

4. Kirkwood SC, Siemers E, Stout JC, Hodes ME, Conneally PM, Christian JC, Foroud T: Longitudinal cognitive and motor changes among presymptomatic Huntington disease gene carriers. Arch Neurol 1999, 56:563-568

5. Peavy GM, Jacobson MW, Goldstein JL, Hamilton JM, Kane A, Gamst AC, Lessig SL, Lee JC, Corey-Bloom J: Cognitive and functional decline in Huntington's disease: dementia criteria revisited. Mov Disord 2010, 25:1163-1169.

6. Bates G, Harper PS, Jones L: Huntington's disease. New York: Oxford University Press; 2002.

7. Chodosh J, Petitti DB, Elliott M, Hays RD, Crooks VC, Reuben DB, Galen Buckwalter J, Wenger N: Physician recognition of cognitive impairment: evaluating the need for improvement. J Am Geriatr SoC 2004, 52:1051-1059.

8. Folstein MF, Folstein SE, McHugh PR: "Mini-mental state". A practical method for grading the cognitive state of patients for the clinician. J Psychiatr Res 1975, 12:189-198.

9. Tombaugh TN, Mclntyre NJ: The mini-mental state examination: a comprehensive review. J Am Geriatr Soc 1992, 40:922-935.

10. Godefroy O, Fickl A, Roussel M, Auribault C, Bugnicourt JM, Lamy C, Canaple S, Petitnicolas G: Is the Montreal Cognitive Assessment Superior to the Mini-Mental State Examination to Detect Poststroke Cognitive Impairment?: A Study With Neuropsychological Evaluation. Stroke 2011 42:1712-1716.

11. Scazufca M, Almeida OP, Vallada HP, Tasse WA, Menezes PR: Limitations of the Mini-Mental State Examination for screening dementia in a community with low socioeconomic status: results from the Sao Paulo Ageing \& Health Study. Eur Arch Psychiatry Clin Neurosci 2009, 259:8-15.
12. Wind AW, Schellevis FG, Van Staveren G, Scholten RP, Jonker C, Van Eijk JT: Limitations of the Mini-Mental State Examination in diagnosing dementia in general practice. Int J Geriatr Psychiatry 1997, 12:101-108.

13. Nasreddine ZS, Phillips NA, Bedirian V, Charbonneau S, Whitehead V, Collin I, Cummings $\mathrm{J}$, Chertkow H: The Montreal Cognitive Assessment, MoCA: a brief screening tool for mild cognitive impairment. J Am Geriatr Soc 2005, 53:695-699.

14. Gluhm S, Goldstein J, Brown D, Van Liew C, Gilbert PE, Corey-Bloom J: Usefulness of the Montreal Cognitive Assessment (MoCA) in Huntington's disease. Mov Disord 2013, 28:1744-1747.

15. Videnovic A, Bernard B, Fan W, Jaglin J, Leurgans S, Shannon KM: The Montreal Cognitive Assessment as a screening tool for cognitive dysfunction in Huntington's disease. Mov Disord 2010, 25:401-404.

16. Mickes $L$, Jacobson M, Peavy G, Wixted JT, Lessig S, Goldstein JL, Corey-Bloom J: A comparison of two brief screening measures of cognitive impairment in Huntington's disease. Mov Disord 2010, 25:2229-2233

17. Bezdicek O, Majerova V, Novak M, Nikolai T, Ruzicka E, Roth J: Validity of the Montreal Cognitive Assessment in the detection of cognitive dysfunction in Huntington's disease. App/ Neuropsychol Adult 2013, 20:33-40.

18. Huntington Study Group: Unified Huntington's disease rating scale: Reliability and consistency. Movement Disorders 1996, 11:136-142.

19. Sheridan LK, Fitzgerald HE, Adams KM, Nigg JT, Martel MM, Puttler LI, Wong MM, Zucker RA: Normative Symbol Digit Modalities Test performance in a community-based sample. Arch Clin Neuropsychol 2006, 21:23-28.

20. O'Bryant SE, O'Jile JR: Attenuating Demographic Influences on Verbal Fluency and Animal Naming in a Psychiatric Sample. Applied Neuropsychology 2004, 11:208-212.

21. Swanson J: The Delis-Kaplan Executive Function System: A Review. Canadian Journal of School Psychology 2005, 20:117-128.

22. Wechsler D: Wechsler Adult Intelligence Scale - Fourth Edition (WAIS-IV) administration and scoring manual. San Antonio, TX: Psychological Corporation; 2008

23. Smith A: Symbol Digit Modalities Test Manual. Western Psychological Services: Torrance, CA; 2007.

24. Ruff RM, Niemann H, Allen CC, Farrow CE, Wylie T: The Ruff 2 and 7 Selective Attention Test: a neuropsychological application. Percept Mot Skills 1992, 75:1311-1319.

25. Graves RE, Bezeau SC, Fogarty J, Blair R: Boston naming test short forms: a comparison of previous forms with new item response theory based forms. J Clin Exp Neuropsychol 2004, 26:891-902.

26. Unverzagt FW, Morgan OS, Thesiger CH, Eldemire DA, Luseko J, Pokuri S, Hui SL, Hall KS, Hendrie HC: Clinical utility of CERAD neuropsychological battery in elderly Jamaicans. J Int Neuropsychol Soc 1999, 5:255-259.

27. Dalrymple-Alford JC, Livingston L, MacAskill MR, Graham C, Melzer TR, Porter RJ, Watts R, Anderson TJ: Characterizing mild cognitive impairment in Parkinson's disease. Mov Disord 2011, 26:629-636.

28. Gelman A, Hill J: Data analysis using regression and multilevel/hierarchical models. New York: Cambridge University Press; 2007.

29. Efron B: Bootstrap Methods: Another Look at the Jackknife. The Annals of Statistics 1979, 7:1-26.

30. Tabrizi SJ, Scahill Rl, Durr A, Roos RAC, Leavitt BR, Jones R, Landwehrmeyer GB, Fox NC, Johnson H, Hicks SL, Kennard C, Craufurd D, Frost C, Langbehn DR, Reilmann R, Stout JC: Biological and clinical changes in premanifest and early stage Huntington's disease in the TRACK-HD study: the 12-month longitudinal analysis. The Lancet Neurology 2010, 10:31-42.

31. Tabrizi SJ, Reilmann R, Roos RA, Durr A, Leavitt B, Owen G, Jones R, Johnson H, Craufurd D, Hicks SL, Kennard C, Landwehrmeyer B, Stout JC, Borowsky B, Scahill Rl, Frost C, Langbehn DR: Potential endpoints for clinical trials in premanifest and early Huntington's disease in the TRACK-HD study: analysis of 24 month observational data. Lancet Neurol 2012, 11:42-53.

32. Bachoud-Levi AC, Maison P, Bartolomeo P, Boisse MF, Dalla Barba G, Ergis AM, Baudic S, Degos JD, Cesaro P, Peschanski M: Retest effects and cognitive decline in longitudinal follow-up of patients with early HD. Neurology 2001, 56:1052-1058.

33. Snowden J, Craufurd D, Griffiths H, Thompson J, Neary D: Longitudinal evaluation of cognitive disorder in Huntington's disease. J Int Neuropsychol Soc 2001, 7:33-44.

34. Lawrence AD, Sahakian BJ, Hodges JR, Rosser AE, Lange KW, Robbins TW: Executive and mnemonic functions in early Huntington's disease. Brain 1996, 119(Pt 5):1633-1645. 
35. Ho AK, Sahakian BJ, Brown RG, Barker RA, Hodges JR, Ane MN, Snowden J, Thompson J, Esmonde T, Gentry R, Moore JW, Bodner T: Profile of cognitive progression in early Huntington's disease. Neurology 2003, 61:1702-1706.

36. Lemiere J, Decruyenaere M, Evers-Kiebooms G, Vandenbussche E, Dom R: Cognitive changes in patients with Huntington's disease (HD) and asymptomatic carriers of the HD mutation-a longitudinal follow-up study. J Neurol 2004, 251:935-942.

37. McCaffrey RJ, Westervelt HJ: Issues associated with repeated neuropsychological assessments. Neuropsychol Rev 1995, 5:203-221.

38. Salthouse TA, Tucker-Drob EM: Implications of short-term retest effects for the interpretation of longitudinal change. Neuropsychology 2008, 22:800-811.

39. Collie A, Maruff P, Darby DG, McStephen M: The effects of practice on the cognitive test performance of neurologically normal individuals assessed at brief test-retest intervals. J Int Neuropsychol Soc 2003, 9:419-428.

40. Falleti MG, Maruff P, Collie A, Darby DG: Practice effects associated with the repeated assessment of cognitive function using the CogState battery at 10-minute, one week and one month test-retest intervals. J Clin Exp Neuropsychol 2006, 28:1095-1112.

41. Bartels C, Wegrzyn M, Wiedl A, Ackermann V, Ehrenreich H: Practice effects in healthy adults: a longitudinal study on frequent repetitive cognitive testing. BMC Neurosci 2010, 11:118.

42. Roth J, Klempii J, Jech R, Zidovska J, Uhrova T, Doubek P, Ulmanova O, Brozova H, Volfova M, Serranova T, Ruzicka E: Caudate nucleus atrophy in Huntington's disease and its relationship with clinical and genetic parameters. Funct Neurol 2005, 20:127-130.

43. Bowie $\mathrm{P}$, Branton T, Holmes J: Should the Mini Mental State Examination be used to monitor dementia treatments?. The Lancet 1999, 354:1527-1528.

44. Clark CM, Sheppard L, Fillenbaum GG, Galasko D, Morris JC, Koss E, Mohs R, Heyman A: Variability in annual Mini-Mental State Examination score in patients with probable Alzheimer disease: a clinical perspective of data from the Consortium to Establish a Registry for Alzheimer's Disease. Arch Neurol 1999, 56:857-862.

45. Larner AJ, Julayanont P, Phillips N, Chertkow H, Nasreddine Z: Montreal Cognitive Assessment (MoCA): Concept and Clinical Review. In Cognitive Screening Instruments. London: Springer; 2013:111-151.

46. Jauhar S, Ritchie S: Psychiatric and behavioural manifestations of Huntington's disease. Advances in Psychiatric Treatment 2010, 16:168-175.

47. Phillips W, Shannon KM, Barker RA: The current clinical management of Huntington's disease. Mov Disord 2008, 23:1491-1504.

48. Rao AK, Gordon AM, Marder KS: Coordination of fingertip forces during precision grip in premanifest Huntington's disease. Mov Disord 2011 26:862-869.

doi:10.1186/2047-9158-3-15

Cite this article as: Toh et al:: Comparison of cognitive and UHDRS measures in monitoring disease progression in Huntington's disease: a 12-month longitudinal study. Translational Neurodegeneration 2014 3:15.

\section{Submit your next manuscript to BioMed Central and take full advantage of:}

- Convenient online submission

- Thorough peer review

- No space constraints or color figure charges

- Immediate publication on acceptance

- Inclusion in PubMed, CAS, Scopus and Google Scholar

- Research which is freely available for redistribution

Submit your manuscript at www.biomedcentral.com/submit
Ciomed Central 